\title{
Psoriasis: An Immunogenetic Perspective
}

\author{
Ayca Kocaaga $^{1}$ Mustafa Kocaaga ${ }^{2}$ \\ ${ }^{1}$ Department of Medical Genetics, Eskişehir City Hospital, Eskisehir, \\ Turkey \\ ${ }^{2}$ Department of Medical Microbiology, Yunus Emre State Hospital, \\ Eskisehir, Turkey
}

\begin{abstract}
Address for correspondence Ayca Kocaaga, Department of Medical Genetics, Eskisehir City Hospital, 71 Evler Mahallesi, Çavdarlar Sokak, TR 26080 Odunpazari, Eskisehir, Türkey

(e-mail: dr.aycacelikmakas@hotmail.com).
\end{abstract}

Glob Med Genet 2022;9:82-89.

\begin{abstract}
Keywords

- autoimmune

- genome-wide association study

- immunogenetics

- psoriasis

Psoriasis is an erythematous-squamous dermatosis with a polygenic inheritance history. Both environmental and genetic factors play a role in the etiology of the disease. Over the past two decades, numerous linkage analyzes and genome-wide association studies have been conducted to investigate the role of genetic variation in disease pathogenesis and progression. To date, $>70$ psoriasis susceptibility loci have been identified, including HLA-Cw6, IL12B, IL23R, and LCE3B/3C. Some genetic markers are used in clinical diagnosis, prognosis, treatment, and personalized new drug development that can further explain the pathogenesis of psoriasis. This review summarizes the immunological mechanisms involved in the etiopathogenesis of psoriasis and recent advances in susceptibility genes and highlights new potential targets for therapeutic intervention.
\end{abstract}

\section{Introduction}

Psoriasis is a clinically common chronic inflammatory disease characterized by skin tissue damage and concomitant other systemic complications. ${ }^{1,2}$ Although psoriasis is more common in American, Canadian, and European populations, it is seen all over the world affecting $\sim 1$ to $3 \%$ of the world's population. ${ }^{3}$ This disease usually presents with clinical and histological features such as adherent, raised silver scales, dividing lines, and oval-shaped plaques with erythema. ${ }^{4}$ Psoriasis is considered to occur through chronic interactions between hyperproliferative keratinocytes and activated immune cells. In recent years, cellular and molecular contributions have been demonstrated in response to an overactive immune response. ${ }^{5}$ Since psoriasis is a skin-specific autoimmune disease, cytokines, chemokines, adhesion factors, epidermal growth factors, nerve growth factors, and especially Th1 and Th17 polarization play a role in its pathogenesis (-Fig. 1). ${ }^{6}$ Although the exact cause of psoriasis is unknown, its genetics are complex and multifactorial. In this article, we summarize what is currently known about the immunogenetics of psoriasis pathogenesis.

received

November 29, 2021

accepted

December 29, 2021

\section{The Immunogenetics of Psoriasis}

\section{HLA-C}

The first gene known to be susceptible to psoriasis is HLACw6, located at chromosome location 6p21 (PSORS1). HLA-C encodes an major histocompatibility complex (MHC) class I receptor involved in the immune system and is involved in the presentation of antigens to CD8 $+\mathrm{T}$ lymphocytes. ${ }^{7}$ In recent years, many studies have been conducted to examine the contribution of the HLA-Cw6 allele to the pathogenesis of psoriasis. ${ }^{8}$ The prevalence of HLA-Cw6 varies worldwide, $\pm 16 \%$ in Africa, 8.5 to $12 \%$ in Europe, and 3.5 to $7.8 \%$ in Asia. ${ }^{9}$ In a study, psoriasis was also associated with HLA-C ${ }^{*} 12: 03 .{ }^{10}$ The HLA-C*12:02 allele was related with late-onset disease in Japanese patients. ${ }^{11}$

\section{ERAP1}

The endoplasmic reticulum aminopeptidase 1 (ERAP1) gene, which belongs to the M1-aminopeptidase family, is located on chromosome 5q15. ERAP1 is involved in processing peptides for MHC class I presentation. ${ }^{12}$ A genome-wide association study (GWAS) demonstrated a significant

\section{(c) 2022. The Author(s).}

This is an open access article published by Thieme under the terms of the Creative Commons Attribution License, permitting unrestricted use, distribution, and reproduction so long as the original work is properly cited. (https://creativecommons.org/licenses/by/4.0/) Georg Thieme Verlag KG, Rüdigerstraße 14, 70469 Stuttgart, Germany 


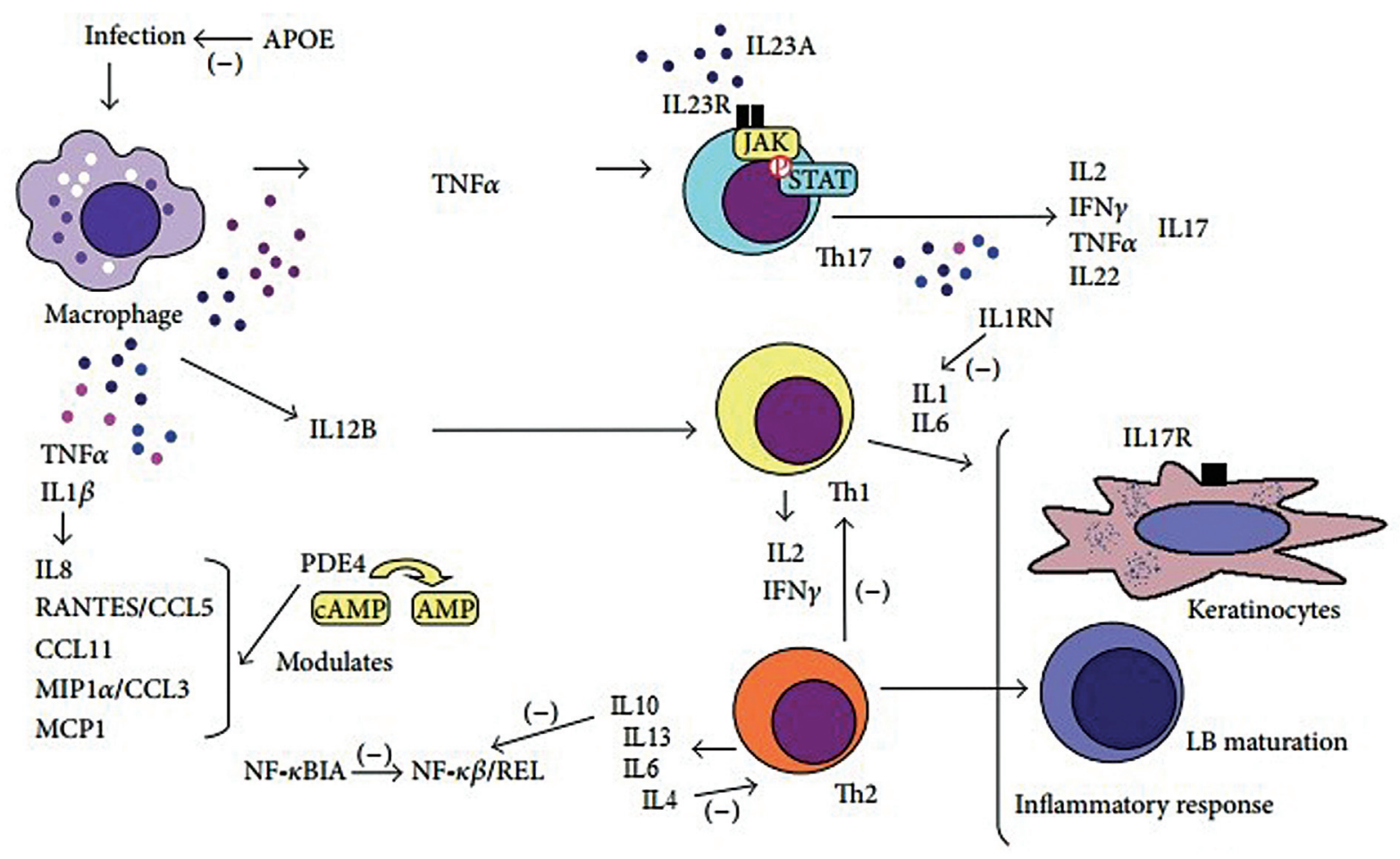

Fig. 1 Summary of cytokine involvement in the pathogenesis of psoriasis.

interaction between the HLA-Cw6 allele and the rs27524 ERAP1 polymorphism. ${ }^{13}$ ERAP1 is involved in processing peptides for MHC class I presentation. The rs30187 (C/T) and rs27524 (G/A) polymorphisms of ERAP1 were found to be associated with increased risk of psoriasis in a Chinese cohort. $^{14}$ A recent meta-analysis showed rs27524 and rs30187 polymorphisms and susceptibility to psoriasis, while lack of association was obtained for rs26653 and rs27044 polymorphisms. ${ }^{15}$

\section{LCE and CDSN}

The PSORS4 locus, located on chromosome 1q21, contains genes that continue without completing epidermal differentiation complex (EDC) formation and keratinization. The late keratinized envelope (LCE) gene cluster is located in the PSORS4 locus of chromosome 1q21.3 and is a part of the EDC. ${ }^{16}$ The copy number variation (LCE3C_LCE3B-del) in the LCE cluster was linked with psoriasis in British, Italian, and Spanish populations, but it was not repeated in German or Tunisian cohorts. ${ }^{17-20}$ Interaction between the MHC and LCE was found in Chinese and Dutch populations, the combination of risk alleles in both of the MHC and LCE genes was showed to increased psoriasis. ${ }^{21,22}$ The CDSN gene encodes corneodesmosin, and in the process of keratocyte maturation, the encoded proteins undergo a succession of cleavages and are localized to human epidermis. The CDSN allele 5 $(+619 \mathrm{~T},+1240 \mathrm{G},+1243 \mathrm{C})$ was linked to susceptibility with psoriasis in Caucasian but not in Japanese populations. ${ }^{23} \mathrm{~A}$ meta-analysis showed no significant association between CDSN -619C/T polymorphism and susceptibility to psoriasis in Caucasian and Asian patients. ${ }^{24}$ The minor allele (A) of
(PSORS1C1/CDSN) rs1062470 was shown to increase the disease risk of psoriasis. ${ }^{25}$

\section{KLF4, DEFB4, and GJB2}

Kruppel-like factor 4 (KLF4) is a transcription factor involved in a variety of cellular events, including development, differentiation, proliferation, and apoptosis. In a functional study, KLF4 expression was shown significantly reduced in psoriatic compared with healthy cells. ${ }^{26}$ A GWAS demonstrated that KLF4 was a likely gene for susceptibility of psoriasis. ${ }^{27}$ An increased copy number of DEFB4 has been associated with psoriasis in a study with Dutch psoriasis patients. ${ }^{28}$ DEFB4 gene transcription has been shown to be strikingly reduced in psoriatic keratinocytes of psoriasis patients. ${ }^{29}$ GJB2 gene encodes connexin 26, a gap junction

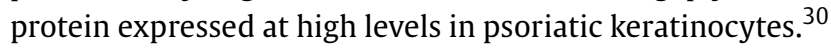
GJB2 showed evidence for association with the German replication cohort, but it was not replicated in an American cohort. $^{31}$ A recent study showed that the CT (rs3751385, GJB2) genotype was protective in late-onset male psoriasis vulgaris, as well as the $\mathrm{T}$ allele in female early-onset psoriasis vulgaris. ${ }^{32}$

\section{IL-1 Gene Family}

Moorchung et al found that there was a strong association between the interleukin (IL)-1 $\beta \mathrm{C} / \mathrm{C}$ genotype and psoriasis. ${ }^{33} \mathrm{~A}$ of study by Tarlow et al showed that the frequency of the A2 allele of IL1RN VNTR increased in the early-onset $(<40$ years) cohort with psoriasis. ${ }^{34}$ A meta-analysis result emphasized that there is no relationship between IL1RN VNTR and psoriasis pathogenesis. ${ }^{35}$ A GWAS showed that the 
(rs397211) IL1RN polymorphism was associated with psoriasis susceptibility. $^{36}$

\section{IL-2, IL-4, IL-6, IL-10, and IL-13}

A study showed that rs2069762 (G allele) in IL-2 conferred a risk of developing the disease, mainly in late-onset psoriasis in a Japanese cohort. ${ }^{37}$ The rs20541 of IL- 4 was found to be associated with psoriasis in a Caucasian population. The GG genotype of IL-6 -174G > C polymorphism was found to be associated with twofold increased risk of the psoriasis. ${ }^{36} \mathrm{Xu}$ et al revealed that two single-nucleotide polymorphisms (SNPs) in IL-6R (rs4845617 and rs2228145) demonstrated an association with psoriasis. ${ }^{38}$ The presence of $C$ allele in the IL-6 SNP rs1800795 decreased the risk of psoriasis. ${ }^{39}$ Moreover, a recent meta-analysis showed that the IL-6 $-174 \mathrm{G} / \mathrm{C}$ polymorphism contributes to psoriasis risk. ${ }^{40}$ Ahmed et al found a higher serum level of IL-6 in Egytptian patients with psoriasis compared to controls. ${ }^{41}$ Craven et al found a significant difference in rs1800896 (IL-10) genotype frequencies between patients and controls. ${ }^{42} \mathrm{~A}$ meta-analysis study indicated that $-1082 \mathrm{G} / \mathrm{A}(\mathrm{rs} 1800896)$ polymorphism confers susceptibility to psoriasis in the Asian population, but there was no risk in Europeans. ${ }^{43}$ There was an association found between rs20541 in IL-13 and psoriasis. $^{44}$ The CCG haplotype of rs1800925, rs20541, and rs848 of IL-13 was found to be associated with susceptibility to psoriasis. ${ }^{45}$

\section{IL-15, IL-17A, IL-17F, and IL17RA}

The polymorphisms in IL-15 (rs2857261, rs10519613, and rs1057972) have been associated with psoriasis in a Chinese subject. ${ }^{46}$ Sanad et al showed that the frequency of GA + AA genotypes of IL-17A was significantly higher in psoriasis cases than in controls. ${ }^{47}$ The T allele and TT genotype of the IL-17F rs763780 polymorphism were associated with a decreased risk of psoriasis. ${ }^{48}$ The IL-17F His161Arg polymorphism was significantly associated with psoriasis based on the genotype and allele analyses in an Asian population. ${ }^{49}$ The IL17RA promoter region (rs4819554) was associated with psoriasis susceptibility in Egyptian psoriatic patients. ${ }^{50}$ A study with Spanish population demonstrated the SNP rs4819554 in the promoter region of IL17RA significantly influenced the response to anti-tumor necrosis factor (TNF) drugs. ${ }^{51}$

\section{IL-18, IL-19, IL-20, and IL20RA}

The minor alleles of the IL-19 gene SNPs (rs2243188, rs2243169, and rs2243158) revealed protective effect to psoriasis and the TGATA haplotype in IL-19 gene proved significant protective effect. ${ }^{52}$ The $\mathrm{G}$ allele of rs1713239 (IL20) was associated with psoriasis susceptibility in a Chinese population. ${ }^{53}$ Kingo et al revealed an association between rs2981572 (IL-20) and predisposition to psoriasis in Caucasian patients. ${ }^{54}$ Moreover, the haplotype in IL-19 and IL-20 was associated a risk factor for the development of psoriasis. ${ }^{55}$ The IL-20 T allele (rs1400986) was found to be linked to protection from psoriasis. ${ }^{56}$ In addition, the polymorphisms in the IL-20 receptor (IL20RA) have also been associated with psoriasis. $^{57}$

\section{IL-12, IL-22, IL-23, and IL23R}

A GWAS showed a reported psoriasis-associated SNP in the IL12B 3' untranslated region (rs3212227). This study also identified two missense SNPs (rs7530511 and rs11209026) in IL23R that associated with psoriasis. ${ }^{58}$ Capon et al found a significant difference between the psoriasis patients and control groups for rs3212227 in IL12B. ${ }^{59}$ A GWAS with a Caucasian population revealed an association between SNPs in IL23R (rs7530511 and rs11209026) and IL12B (rs6887695 and rs3212227) and predisposition to psoriasis. ${ }^{60}$ Liu et al found an association between the IL23R (rs11209026) and IL12B (rs6887695) polymorphisms and psoriasis. ${ }^{61}$ Another recent study also showed a link between rs11209026 of IL23R gene and psoriasis. ${ }^{44}$ A GWAS in Caucasian patients showed the rs2201841 and rs2066808 (IL23R) and rs2082412 and rs2546890 (IL12B) polymorphisms were associated with psoriasis. $^{36}$ The A allele (rs3212227, IL12B) was found more frequent in Japanese patients with psoriasis than in healthy controls. ${ }^{62}$ A GWAS with Chinese population found that the rs6887695 IL12B SNP was associated with psoriasis. $^{63}$ The rs7530511 and rs3212227 (IL23R gene) polymorphisms were associated with psoriasis in a Thai cohort. $^{64}$ The nonsynonymous SNP in IL23R, rs11209026, widely thought to be the primary psoriasis-associated SNP in IL23R in Europeans, was found not to be polymorphic in Chinese. ${ }^{65,66}$

\section{TNF- $\alpha$ and TGF- $\beta 1$}

The TNF- $\alpha$ polymorphisms (rs1800629 and rs361525) linked a strong association in Caucasian patients with early-onset psoriasis. ${ }^{67}$ A meta-analysis study showed that when the $\mathrm{GA}+\mathrm{AA}$ genotype was compared with the GG genotype, the risk of psoriasis increased for rs361525 and decreased for rs1800629 in TNF- $\alpha$ gene. ${ }^{68}$ Moreover, a functional study found an association between the A allele in rs361525 in the TNF- $\alpha$ gene and increased production of TNF- $\alpha$ and earlyonset psoriasis. ${ }^{69}$ A study with an Egyptian case-control revealed an association between TNF- $\alpha$ (GG allele in rs1800629) polymorphism and psoriasis. ${ }^{41}$ Another study with Caucasian patients showed decreased frequency of the GG genotype and increased frequency of the GA genotype of rs361525 (TNF- $\alpha$ gene) in patients with type I (onset before 40 years) psoriasis compared with controls. ${ }^{70} \mathrm{~A}$ recent metaanalysis showed that TNF- $\alpha-238 \mathrm{G} / \mathrm{A},-308 \mathrm{G} / \mathrm{A}$, and $-857 \mathrm{C} / \mathrm{T}$ polymorphisms were associated with elevated susceptibility to psoriasis in certain populations. ${ }^{71}$ TGF- $\beta 1$ gene polymorphism at codon 10 (T869C) is significantly associated with susceptibility to psoriasis in Egyptian patients. ${ }^{72}$ TGF- $\beta 1$ gene polymorphism in codons 10 and 25 are not associated with susceptibility to psoriasis vulgaris in Polish patients. ${ }^{73}$

\section{TNFAIP3 and TRAF3IP2}

TNFAIP3 interacting protein (TNIP1) regulates the activity of nuclear factor kappa B (NF-kB). The rs610604 (TNFAIP3) and rs17728338 (TNIP1) SNPs were associated with psoriasis in a case-control study. ${ }^{44}$ Ellinghaus et al found an association between two SNPs (rs13210247 and rs33980500) in NF receptor-associated factor 3 interacting protein gene and 
psoriasis. ${ }^{74}$ Hüffmeier et al replicated the association in a German population with psoriasis. ${ }^{75}$ A significant association between psoriasis and the SNP rs610604 of TNFAIP3 gene was found in an Egyptian cohort. ${ }^{76}$ In a GWAS, the rs240993 (TRAF3IP2) was associated with psoriasis in Caucasian patients. $^{13}$ A meta-analysis demonstrated that rs610604 in TNFAIP3 and rs17728338 in TNIP1 gene polymorphisms were associated with psoriasis susceptibility. ${ }^{77}$

\section{Toll-Like Receptors}

A study with a Turkish population demonstrated that the TLR2-rs4696480 AA genotype seemed to have a higher risk for psoriasis. ${ }^{78}$ Zabłotna et al found no statistically significant association between Arg753Gln TLR2 and -1237 T/C TLR9 gene polymorphisms and psoriasis in a Polish cohort. ${ }^{79}$ The SNP rs3804099 of TLR2 was linked to psoriasis susceptibility in a Chinese population. ${ }^{80}$ A study from Turkey demonstrated that GA genotype and A allele in TLR2 Arg753Gln polymorphism were associated with psoriasis. ${ }^{81}$

\section{APOE, ACE, ANGPT2, VDR, MTHFR, and VEGF}

Apolipoprotein E (APOE) alleles $\varepsilon 2, \varepsilon 4$, and genotypes $\varepsilon 2 / \varepsilon 3$ and $\varepsilon 4 / \varepsilon 3$ were found to be a risk factor for psoriasis, while allele $\varepsilon 3$ and genotype $\varepsilon 3 / \varepsilon 3$ were associated to be protective factor for psoriasis in a Saudi cohort. ${ }^{82} \mathrm{~A}$ meta-analysis demonstrated that the $\varepsilon 2$ and $\varepsilon 3$ alleles of the APOE polymorphism were associated with the risk of psoriasis. ${ }^{83}$ A meta-analysis showed that the homozygous I/I genotype and I allele increased risk of psoriasis, while the heterozygous I/D genotype decreased risk in Asian but not in Caucasian populations. ${ }^{84}$ The results of the another metaanalysis showed that angiotensin-converting enzyme I/D polymorphism may be associated with psoriasis susceptibility, while ID genotype seemed to have a protective role in Caucasian patients affected by psoriatic arthritis. ${ }^{85}$ The rs2442598 polymorphism of angiopoietin-2 was significantly associated with psoriasis. ${ }^{86}$ The polymorphisms of vitamin $D$ receptor has been found the conflicting results in psoriasis. A meta-analysis showed that the vitamin D receptor (VDR) TaqI polymorphism was associated with psoriasis susceptibility in Caucasian populations. This meta-analysis also indicated the polymorphisms in VDR ApaI, BsmI, and FokI were not associated with psoriasis susceptibility in Caucasian or Asian populations. ${ }^{87}$ Huraib et al showed that the $\mathrm{T}$ allele and TT, CT genotypes of methylenetetrahydrofolate reductase (MTHFR) C677T are significantly linked with psoriasis susceptibility. ${ }^{88}$ A metaanalysis showed that there is no association between MTHFR C677T polymorphism and either Asian or European psoriatic patients. ${ }^{89}$ The $-1154 \mathrm{G}$ allele and $+405 \mathrm{CC}$ and -460 TT genotypes of vascular endothelial growth factor (VEGF) gene demonstrated that there is a significantly increased risk of psoriasis in a Polish cohort. ${ }^{90} \mathrm{~A}$ metaanalysis demonstrated the VEGF $+405 \mathrm{C} / \mathrm{G}$ polymorphism susceptibility to psoriasis in Asians, and the $-460 \mathrm{C} / \mathrm{T}$ and $-1154 \mathrm{~A} / \mathrm{G}$ polymorphisms susceptibility to psoriasis in Europeans. ${ }^{91}$

\section{Inflammasome-Related Genes}

The polymorphism rs10403848 in CARD8 was significantly associated with psoriasis risk in the Chinese Han population. ${ }^{92}$ A CARD11 rs4722404 SNP was also associated with increased risk of early-onset psoriasis in a Chinese population. ${ }^{93}$ Moreover, the CARD10 SNPs were not association with psoriasis in another Chinese population. ${ }^{94}$ The rs11652075 CC (p.Arg820Trp) genotype of CARD14 was significantly associated with psoriasis in a Spanish cohort. ${ }^{95}$ The CARD14 c.526G > C (p.Asp176His) polymorphism was found to be a significant risk factor for generalized pustular psoriasis in a Japanese cohort. ${ }^{96}$ In a study with a Chinese patients, the CC genotype of c.C2458T SNP in the CARD14 was related and associated significantly with an increased familial history with psoriasis. ${ }^{97}$ GWASs have found the SNP c.C2458T in CARD14 gene was associated with psoriasis. ${ }^{98}$ The association between NOD2/CARD15 polymorphisms and psoriasis was not found in a meta-analysis. ${ }^{99}$ The NLRP1 rs8079034C and rs878329C alleles were associated to be a risk factor for psoriasis. ${ }^{100}$ NLRP3 rs10733113 and CARD8 rs2043211 polymorphisms were associated with psoriasis in a Swedish population. ${ }^{101}$ Two SNPs, rs3806265 and rs10754557, in NLRP3 were significantly associated with psoriasis in a Chinese Han population. ${ }^{102}$

\section{The Other Genes}

Kim et al showed JAK2 rs7849191polymorphism was a protective factor for psoriasis in the Korean population. ${ }^{103}$ Sayed et al found a possible association between JAK1 rs310241 and JAK3 rs3008 gene polymorphisms and susceptibility to psoriasis. ${ }^{104}$ The genotypes of rs744166GG in STAT3 and rs7574865TT in STAT4 were found higher in psoriasis patients than the controls in Northeastern China. ${ }^{105}$ The rs1020760 at NF-KB1 was associated with family history of psoriasis in a Chinese cohort. ${ }^{106}$ The rs2847297, rs657555, and rs482160 polymorphisms of PTPN2 gene were significantly associated with psoriasis. ${ }^{107}$ The (1858C/T) R620W polymorphism of PTPN22 was found to be positively linked with susceptibility of psoriasis in Saudis. ${ }^{108}$ A study with a Turkish population demonstrated that Vaspin rs2236242 polymorphism was related to psoriasis. ${ }^{109}$ A meta-analysis demonstrated that the CD143 ID polymorphism linked the risk of psoriasis in individuals with East Asian. ${ }^{110}$ The G allele of PD1.6 increased the risk of psoriasis in the Chinese subjects. ${ }^{111}$ The frequency of the rs2787094 C allele of ADAM33 gene was significantly linked with psoriasis in a Han population. ${ }^{112}$ The HCP5 gene $335 \mathrm{~T}>$ $\mathrm{G}$ polymorphism was associated with the increased risk of developing psoriasis in the Indian patients. ${ }^{113}$

\section{Conclusion}

Psoriasis is an incurable disease that negatively affects the quality of life of affected individuals. Although the exact cause of psoriasis remains unknown, immune factors play a very important role in its pathogenesis. In recent years, more 
than 70 psoriasis susceptibility loci have been associated. However, the identified genes account for approximately one-third of the heritability of psoriasis, suggesting the existence of additional yet unidentified sources of inheritance. Indeed, in the case of complex hereditary diseases such as psoriasis, it turned out that the identification of genetic risk factors is not sufficient to predict the development of the disease or assess its severity. Current management of psoriatic patients is a real challenge for clinicians. Recent therapeutic recommendations regarding the place of biotherapies are based directly on immunological mechanisms that have recently been elucidated. Advances in biology have certainly made it possible in recent years to elucidate many aspects of the pathogenesis of psoriasis, but have not answered the main questions regarding the nature of the antigen and/or the genes responsible. Answering these questions could lead to the development of more targeted and effective treatments, curative and even preventative treatments.

\section{Authors' Contributions}

A.K. did the conceptualization. M.K. made a figure. Manuscript preparation, writing, and editing were done by A.K. and M.K.

\section{Conflict of Interest \\ None declared.}

\section{References}

1 Gisondi P, Bellinato F, Girolomoni G, Albanesi C. Pathogenesis of chronic plaque psoriasis and its intersection with cardio-metabolic comorbidities. Front Pharmacol 2020;11:117

2 Liu T, Li S, Ying S, et al. The IL-23/IL-17 pathway in inflammatory skin diseases: from bench to bedside. Front Immunol 2020; 11:594735

3 Parisi R, Iskandar IYK, Kontopantelis E, Augustin M, Griffiths CEM, Ashcroft DMGlobal Psoriasis Atlas. National, regional, and worldwide epidemiology of psoriasis: systematic analysis and modelling study. BMJ 2020;369:m1590

$4 \mathrm{Xu} \mathrm{X}$, Zhang HY. The immunogenetics of psoriasis and implications for drug repositioning. Int J Mol Sci 2017;18(12):E2650

5 Harden JL, Krueger JG, Bowcock AM. The immunogenetics of psoriasis: a comprehensive review. J Autoimmun 2015;64:66-73

6 Karczewski J, Dobrowolska A, Rychlewska-Hańczewska A, Adamski Z. New insights into the role of T cells in pathogenesis of psoriasis and psoriatic arthritis. Autoimmunity 2016;49(07): 435-450

7 Membrive Jiménez C, Pérez Ramírez C, Sánchez Martín A, et al. Influence of genetic polymorphisms on response to biologics in moderate-to-severe psoriasis. J Pers Med 2021;11(04):293

8 Caputo V, Strafella C, Termine A, et al. Overview of the molecular determinants contributing to the expression of psoriasis and psoriatic arthritis phenotypes. J Cell Mol Med 2020;24(23): 13554-13563

9 Gourraud PA, Khankhanian P, Cereb N, et al. HLA diversity in the 1000 Genomes dataset. PLoS One 2014;9(07):e97282

10 Helms C, Saccone NL, Cao L, et al. Localization of PSORS1 to a haplotype block harboring HLA-C and distinct from corneodesmosin and HCR. Hum Genet 2005;118(3-4):466-476

11 Mabuchi T, Ota T, Manabe Y, et al. HLA-C ${ }^{*} 12: 02$ is a susceptibility factor in late-onset type of psoriasis in Japanese. J Dermatol 2014;41(08):697-704
12 Jadon D, Tillett W, Wallis D, et al. Exploring ankylosing spondylitis-associated ERAP1, IL23R and IL12B gene polymorphisms in subphenotypes of psoriatic arthritis. Rheumatology (Oxford) 2013;52(02):261-266

13 Strange A, Capon F, Spencer CC, et al; Genetic Analysis of Psoriasis Consortium \& the Wellcome Trust Case Control Consortium 2A genome-wide association study identifies new psoriasis susceptibility loci and an interaction between HLA-C and ERAP1. Nat Genet 2010;42(11):985-990

$14 \mathrm{WuX}$, Zhao Z. Associations between ERAP1 gene polymorphisms and psoriasis susceptibility: a meta-analysis of case-control studies. BioMed Res Int 2021;2021:5515868

15 Zavattaro E, Ramezani M, Sadeghi M. Endoplasmic reticulum aminopeptidase 1 (ERAP1) polymorphisms and psoriasis susceptibility: a systematic review and meta-analysis. Gene 2020; 736:144416

16 Zhang XJ, Huang W, Yang S, et al. Psoriasis genome-wide association study identifies susceptibility variants within LCE gene cluster at 1q21. Nat Genet 2009;41(02):205-210

17 Bowes J, Flynn E, Ho P, et al. Variants in linkage disequilibrium with the late cornified envelope gene cluster deletion are associated with susceptibility to psoriatic arthritis. Ann Rheum Dis 2010;69(12):2199-2203

18 Docampo E, Rabionet R, Riveira-Muñoz E, et al. Deletion of the late cornified envelope genes, LCE3C and LCE3B, is associated with rheumatoid arthritis. Arthritis Rheum 2010;62(05): 1246-1251

19 Chiraz BS, Myriam A, Ines Z, et al. Deletion of late cornified envelope genes, LCE3C_LCE3B-del, is not associated with psoriatic arthritis in Tunisian patients. Mol Biol Rep 2014;41(06): 4141-4146

20 Docampo E, Giardina E, Riveira-Muñoz E, et al. Deletion of LCE3C and LCE3B is a susceptibility factor for psoriatic arthritis: a study in Spanish and Italian populations and meta-analysis. Arthritis Rheum 2011;63(07):1860-1865

21 Zheng HF, Zuo XB, Lu WS, et al. Variants in MHC, LCE and IL12B have epistatic effects on psoriasis risk in Chinese population. J Dermatol Sci 2011;61(02):124-128

22 Li M, Wu Y, Chen G, et al. Deletion of the late cornified envelope genes LCE3C and LCE3B is associated with psoriasis in a Chinese population. J Invest Dermatol 2011;131(08):1639-1643

23 Ameen M, Allen MH, Fisher SA, et al. Corneodesmosin (CDSN) gene association with psoriasis vulgaris in Caucasian but not in Japanese populations. Clin Exp Dermatol 2005;30(04):414-418

24 Wu Y, Wang B, Liu JL, Gao XH, Chen HD, Li YH. Association of $-619 \mathrm{C} / \mathrm{T}$ polymorphism in CDSN gene and psoriasis risk: a metaanalysis. Genet Mol Res 2011;10(04):3632-3640

25 Wiśniewski A, Matusiak Ł, Szczerkowska-Dobosz A, Nowak I, Kuśnierczyk P. HLA-C ${ }^{*}$ 06:02-independent, gender-related association of PSORS1C3 and PSORS1C1/CDSN single-nucleotide polymorphisms with risk and severity of psoriasis. Mol Genet Genomics 2018;293(04):957-966

26 Madonna S, Scarponi C, Sestito R, Pallotta S, Cavani A, Albanesi C. The IFN-gamma-dependent suppressor of cytokine signaling 1 promoter activity is positively regulated by IFN regulatory factor-1 and Sp1 but repressed by growth factor independence-1b and Krüppel-like factor-4, and it is dysregulated in psoriatic keratinocytes. J Immunol 2010;185(04):2467-2481

27 Ray-Jones H, Duffus K, McGovern A, et al. Mapping DNA interaction landscapes in psoriasis susceptibility loci highlights KLF4 as a target gene in 9q31. BMC Biol 2020;18(01):47

28 Hollox EJ, Huffmeier U, Zeeuwen PL, et al. Psoriasis is associated with increased beta-defensin genomic copy number. Nat Genet 2008;40(01):23-25

29 Niyonsaba F, Ogawa H, Nagaoka I. Human beta-defensin-2 functions as a chemotactic agent for tumour necrosis factoralpha-treated human neutrophils. Immunology 2004;111(03): 273-281 
30 Labarthe MP, Bosco D, Saurat JH, Meda P, Salomon D. Upregulation of connexin 26 between keratinocytes of psoriatic lesions. J Invest Dermatol 1998;111(01):72-76

31 Sun LD, Cheng H, Wang ZX, et al. Association analyses identify six new psoriasis susceptibility loci in the Chinese population. Nat Genet 2010;42(11):1005-1009

32 Stylianaki EA, Karpouzis A, Tripsianis G, Veletza S. Assessment of gap junction protein beta-2 rs3751385 gene polymorphism in psoriasis vulgaris. J Clin Med Res 2019;11(09):642-650

33 Moorchung N, Vasudevan B, Chatterjee M, Mani NS, Grewal RS. Interleukin-1 gene polymorphisms and their relation with NFKB expression and histopathological features in psoriasis. Indian $\mathrm{J}$ Dermatol 2015;60(05):432-438

34 Tarlow JK, Cork MJ, Clay FE, et al. Association between interleukin-1 receptor antagonist (IL-1ra) gene polymorphism and early and late-onset psoriasis. Br J Dermatol 1997;136(01): 147-148

35 Qiao J, Jia QN, Jin HZ. Lack of association of the IL-1RN and IL-10 polymorphisms with risk of psoriasis: a meta-analysis. Mol Genet Genomic Med 2019;7(01):e00512

36 Nair RP, Duffin KC, Helms C, et al; Collaborative Association Study of Psoriasis. Genome-wide scan reveals association of psoriasis with IL-23 and NF-kappaB pathways. Nat Genet 2009;41(02): 199-204

37 Kim YK, Pyo CW, Choi HB, Kim SY, Kim TY, Kim TG. Associations of IL-2 and IL-4 gene polymorphisms with psoriasis in the Korean population. J Dermatol Sci 2007;48(02):133-139

$38 \mathrm{Xu} \mathrm{H}$, Liu J, Niu M, et al. Soluble IL-6R-mediated IL-6 transsignaling activation contributes to the pathological development of psoriasis. J Mol Med (Berl) 2021;99(07):1009-1020

39 Boca AN, Talamonti M, Galluzzo M, et al. Genetic variations in IL6 and IL12B decreasing the risk for psoriasis. Immunol Lett 2013; 156(1-2):127-131

40 Nie G, Xie CL, Cao YJ, et al. Meta-analysis of IL-6 -174G/C polymorphism and psoriasis risk. Genet Mol Res 2016;15(02):

41 Elneam AIA, Al-Dhubaibi MS, Alrheam A. Angiotensin-Converting Enzyme (ACE) D Allele as a risk factor for Increase Serum Interleukin- 6 and Interleukin- 8 in psoriasis patients. Open Access Maced J Med Sci 2018;6(05):772-776

42 Craven NM, Jackson CW, Kirby B, et al. Cytokine gene polymorphisms in psoriasis. Br J Dermatol 2001;144(04):849-853

43 Lee YH, Choi SJ, Ji JD, Song GG. Associations between interleukin10 polymorphisms and susceptibility to psoriasis: a meta-analysis. Inflamm Res 2012;61(07):657-663

44 Julià A, Tortosa R, Hernanz JM, et al. Risk variants for psoriasis vulgaris in a large case-control collection and association with clinical subphenotypes. Hum Mol Genet 2012;21(20): 4549-4557

45 Chang M, Li Y, Yan C, et al. Variants in the 5q31 cytokine gene cluster are associated with psoriasis. Genes Immun 2008;9(02): 176-181

46 Zhang XJ, Yan KL, Wang ZM, et al. Polymorphisms in interleukin15 gene on chromosome $4 \mathrm{q} 31.2$ are associated with psoriasis vulgaris in Chinese population. J Invest Dermatol 2007;127(11): 2544-2551

47 Sanad EMK, Nazmy NN, Abd-El Hamid El Sayed R, Hamed AM. Interleukin-17A gene single nucleotide polymorphism and its relation to fungal growth in psoriatic patients: a preliminary study. J Cosmet Dermatol 2021

48 Villalpando-Vargas FV, Rivera-Valdés JJ, Alvarado-Navarro A, et al. Association between IL-17A, IL-17F and IL-17RA gene polymorphisms and susceptibility to psoriasis and psoriatic arthritis: a meta-analysis. Inflamm Res 2021;70(1012):1201-1210

49 Choi BG, Hong JY, Hong JR, et al. The IL17F His161Arg polymorphism, a potential risk locus for psoriasis, increases serum levels of interleukin-17F in an Asian population. Sci Rep 2019;9(01): 18921
50 Sabry D, Aboraia N, Samir M. A potential association between psoriasin to rs4819554 of IL-17RA gene polymorphism in psoriasis Egyptian patients. Arch Dermatol Res 2020;312(04): 273-281

51 Batalla A, Coto E, Gómez J, et al. IL17RA gene variants and antiTNF response among psoriasis patients. Pharmacogenomics J 2018;18(01):76-80

52 Kõks S, Kingo K, Rätsep R, Karelson M, Silm H, Vasar E. Combined haplotype analysis of the interleukin-19 and -20 genes: relationship to plaque-type psoriasis. Genes Immun 2004;5(08): 662-667

53 Chen XY, Jin LW, Chen YW, et al. The association between the IL$20-1723 \mathrm{C} \rightarrow \mathrm{G}$ allele on the $1 \mathrm{q}$ chromosome and psoriasis triggered or exacerbated by an upper respiratory tract infection in the Chinese Han population. Dermatology 2011;222(01):24-30

54 Kingo K, Kõks S, Nikopensius T, Silm H, Vasar E. Polymorphisms in the interleukin-20 gene: relationships to plaque-type psoriasis. Genes Immun 2004;5(02):117-121

55 Kõks S, Kingo K, Vabrit K, et al. Possible relations between the polymorphisms of the cytokines IL-19, IL-20 and IL-24 and plaque-type psoriasis. Genes Immun 2005;6(05):407-415

56 Galimova E, Rätsep R, Traks T, Kingo K, Escott-Price V, Kõks S. Interleukin-10 family cytokines pathway: genetic variants and psoriasis. Br J Dermatol 2017;176(06):1577-1587

57 Kingo K, Mössner R, Traks T, et al. Further association analysis of chr 6q22-24 suggests a role of IL-20RA polymorphisms in psoriasis. J Dermatol Sci 2010;57(01):71-73

58 Cargill M, Schrodi SJ, Chang M, et al. A large-scale genetic association study confirms IL12B and leads to the identification of IL23R as psoriasis-risk genes. Am J Hum Genet 2007;80(02): 273-290

59 Capon F, Di Meglio P, Szaub J, et al. Sequence variants in the genes for the interleukin-23 receptor (IL23R) and its ligand (IL12B) confer protection against psoriasis. Hum Genet 2007;122(02): 201-206

60 Nair RP, Ruether A, Stuart PE, et al. Polymorphisms of the IL12B and IL23R genes are associated with psoriasis. J Invest Dermatol 2008;128(07):1653-1661

61 Liu Y, Helms C, Liao W, et al. A genome-wide association study of psoriasis and psoriatic arthritis identifies new disease loci. PLoS Genet 2008;4(03):e1000041

62 Tsunemi Y, Saeki H, Nakamura K, et al. Interleukin-12 p40 gene (IL12B) 3'-untranslated region polymorphism is associated with susceptibility to atopic dermatitis and psoriasis vulgaris. J Dermatol Sci 2002;30(02):161-166

$63 \mathrm{Wu} \mathrm{Y,} \mathrm{Lu} \mathrm{Z,} \mathrm{Chen} \mathrm{Y,} \mathrm{Xue} \mathrm{F,} \mathrm{Chen} \mathrm{X,} \mathrm{Zheng} \mathrm{J.} \mathrm{Replication} \mathrm{of}$ association between interleukin-23 receptor (IL-23R) and its ligand (IL-12B) polymorphisms and psoriasis in the Chinese Han population. Hum Immunol 2010;71(12):1255-1258

64 Nair RP, Stuart PE, Kullavanijaya P, et al. Genetic evidence for involvement of the IL23 pathway in Thai psoriatics. Arch Dermatol Res 2010;302(02):139-143

65 Davidson SI, Wu X, Liu Y, et al. Association of ERAP1, but not IL23R, with ankylosing spondylitis in a Han Chinese population. Arthritis Rheum 2009;60(11):3263-3268

$66 \mathrm{Li} \mathrm{XL}, \mathrm{Wu} \mathrm{CF}, \mathrm{Wu}$ GS. Genetic variations of cytokines and cytokine receptors in psoriasis patients from China. Int J Genomics 2014; 2014:870597

67 Höhler T, Kruger A, Schneider PM, et al. A TNF-alpha promoter polymorphism is associated with juvenile onset psoriasis and psoriatic arthritis. J Invest Dermatol 1997;109(04):562-565

68 Li C, Wang G, Gao Y, Liu L, Gao T. TNF-alpha gene promoter $-238 \mathrm{G}>\mathrm{A}$ and $-308 \mathrm{G}>\mathrm{A}$ polymorphisms alter risk of psoriasis vulgaris: a meta-analysis. J Invest Dermatol 2007;127(08): 1886-1892

69 Reich K, Mössner R, König IR, Westphal G, Ziegler A, Neumann C. Promoter polymorphisms of the genes encoding tumor necrosis factor-alpha and interleukin-1beta are associated with different 
subtypes of psoriasis characterized by early and late disease onset. J Invest Dermatol 2002;118(01):155-163

70 Arias AI, Giles B, Eiermann TH, Sterry W, Pandey JP. Tumor necrosis factor-alpha gene polymorphism in psoriasis. Exp Clin Immunogenet 1997;14(02):118-122

71 Wang L, Zhou H. A meta-analysis of the relationship between tumor necrosis factor- $\alpha$ polymorphisms and psoriasis. Dermatology 2021;237(01):39-45

72 El-Hadidi HH, Hassan AS, El-Hanafy G, Amr KS, Abdelmesih SF, Abdelhamid MF. Transforming growth factor- $\beta 1$ gene polymorphism in psoriasis vulgaris. Clin Cosmet Investig Dermatol 2018; 11:415-419

73 Baran W, Szepietowski JC, Mazur G, Baran E. TGF-beta(1) gene polymorphism in psoriasis vulgaris. Cytokine 2007;38(01): 8-11

74 Ellinghaus E, Ellinghaus D, Stuart PE, et al. Genome-wide association study identifies a psoriasis susceptibility locus at TRAF3IP2. Nat Genet 2010;42(11):991-995

75 Hüffmeier $U$, Uebe $S$, Ekici $A B$, et al. Common variants at TRAF3IP2 are associated with susceptibility to psoriatic arthritis and psoriasis. Nat Genet 2010;42(11):996-999

76 Haase O, Mosaad H, Eldarouti MA, et al. TNFAIP3 and IL12B gene polymorphisms associated with psoriasis vulgaris in an Egyptian cohort. J Eur Acad Dermatol Venereol 2015;29(07): 1297-1301

77 Gong HB, Gao ST, Pu XM, Kang XJ, Wu XJ. Association of rs610604 in TNFAIP3 and rs17728338 in TNIP1 gene polymorphisms with psoriasis susceptibility: a meta-analysis of case-control studies. BMC Med Genet 2020;21(01):103

78 Sabah-Özcan S, Gürel G. The polymorphism rs4696480 in the TLR2 gene is associated with psoriasis patients in the Turkish population. Immunol Lett 2019;211:28-32

79 Zabłotna M, Sobjanek M, Purzycka-Bohdan D, SzczerkowskaDobosz A, Nedoszytko B, Nowicki RJ. The significance of Toll-like receptor (TLR) 2 and 9 gene polymorphisms in psoriasis. Postepy Dermatol Alergol 2017;34(01):85-86

80 Shi G, Wang T, Li S, et al. TLR2 and TLR4 polymorphisms in Southern Chinese psoriasis vulgaris patients. J Dermatol Sci 2016;83(02):145-147

81 Çakmak G, Dursun A. Relationship between TLR2 and TLR4 gene polymorphisms with psoriasis. Turk J Dermatol 2018;12:28-32

82 Al Harthi F, Huraib GB, Zouman A, Arfin M, Tariq M, Al-Asmari A. Apolipoprotein E gene polymorphism and serum lipid profile in Saudi patients with psoriasis. Dis Markers 2014; 2014:239645

83 Han Y, Liu T, Lu L. Apolipoprotein E gene polymorphism in psoriasis: a meta-analysis. Arch Med Res 2013;44(01):46-53

84 Stefanic M, Rucevic I, Barisic-Drusko V. Meta-analysis of vitamin D receptor polymorphisms and psoriasis risk. Int J Dermatol 2013;52(06):705-710

85 Ramezani M, Zavattaro E, Sadeghi M. Angiotensin-converting enzyme gene insertion/deletion polymorphism and susceptibility to psoriasis: a systematic review and meta-analysis. BMC Med Genet 2020;21(01):8

86 He L, Dang L, Zhou J, Bai J, Li YZ. Association of angiopoietin-1, angiopoietin-2 and caspase-5 polymorphisms with psoriasis vulgaris. Clin Exp Dermatol 2015;40(05):556-563

87 Lee YH. Vitamin D receptor ApaI, TaqI, BsmI, and FokI polymorphisms and psoriasis susceptibility: an updated meta-analysis. Clin Exp Dermatol 2019;44(05):498-505

88 Huraib GB, Harthi FA, Arfin M, Khlaiwi AA, Rizvi S, Al-Asmari A. Methylenetetrahydrofolate Reductase C677T gene polymorphism as risk factor for psoriasis in Saudis. Biomark Insights 2019; 14:1177271919830973

89 Wu D, Shi D, Yang L, Zhu X. Association between methylenetetrahydrofolate reductase C677T polymorphism and psoriasis: a meta-analysis. J Dermatol 2016;43(02):162-169
90 Zablotna M, Sobjanek M, Nedoszytko B, et al. Association of psoriasis with the VEGF gene polymorphism in the northern Polish population. J Eur Acad Dermatol Venereol 2013;27(03): 319-323

91 Lee YH, Song GG. Vascular endothelial growth factor gene polymorphisms and psoriasis susceptibility: a meta-analysis. Genet Mol Res 2015;14(04):14396-14405

92 Yu P, Liu B, Hao S, Xing R, Li Y. A new risk polymorphism rs10403848 of CARD8 significantly associated with psoriasis vulgaris in Northeastern China. BioMed Res Int 2020; 2020:2867505

93 Shi G, Cheng CM, Wang TT, Li SJ, Fan YM, Zhu KJ. Association between atopic dermatitis-related single nucleotide polymorphisms rs4722404 and psoriasis vulgaris in a southern Chinese cohort. Genet Mol Res 2016;15(02)

94 Shi G, Zhang MF, Liao PY, et al. Lack of association between CARD10/CARMA3 tag SNPs and psoriasis vulgaris in the southern Chinese population. Genet Mol Res 2017;16(01):

95 González-Lara L, Coto-Segura P, Penedo A, et al. SNP rs11652075 in the CARD14 gene as a risk factor for psoriasis (PSORS2) in a Spanish cohort. DNA Cell Biol 2013;32(10):601-604

96 Sugiura K, Muto M, Akiyama M. CARD14 c.526G >C (p. Asp176His) is a significant risk factor for generalized pustular psoriasis with psoriasis vulgaris in the Japanese cohort. J Invest Dermatol 2014;134(06):1755-1757

97 Feng C, Wang T, Li SJ, Fan YM, Shi G, Zhu KJ. CARD14 gene polymorphism c.C2458T (p.Arg820Trp) is associated with clinical features of psoriasis vulgaris in a Chinese cohort. J Dermatol 2016;43(03):294-297

98 Shi G, Li SJ, Wang TT, Cheng CM, Fan YM, Zhu KJ. The common CARD14 gene missense polymorphism rs11652075 (c.C2458T/p. Arg820Trp) is associated with psoriasis: a meta-analysis. Genet Mol Res 2016;15(03):

99 Zhu K, Yin X, Tang X, Zhang F, Yang S, Zhang X. Meta-analysis of NOD2/CARD15 polymorphisms with psoriasis and psoriatic arthritis. Rheumatol Int 2012;32(07):1893-1900

100 Ekman AK, Verma D, Fredrikson M, Bivik C, Enerbäck C. Genetic variations of NLRP1: susceptibility in psoriasis. $\mathrm{Br} \mathrm{J}$ Dermatol 2014;171(06):1517-1520

101 Carlström M, Ekman AK, Petersson S, Söderkvist P, Enerbäck C. Genetic support for the role of the NLRP3 inflammasome in psoriasis susceptibility. Exp Dermatol 2012;21(12):932-937

$102 \mathrm{Yu}$ P, Hao S, Zheng H, Zhao X, Li Y. Association of NLRP1 and NLRP3 polymorphisms with psoriasis vulgaris risk in the Chinese Han population. BioMed Res Int 2018;2018:4714836

103 Kim SY, Hur MS, Choi BG, et al. A preliminary study of new single polymorphisms in the $T$ helper type 17 pathway for psoriasis in the Korean population. Clin Exp Immunol 2017;187(02): 251-258

104 Sayed KS, El-Komy MHM, Shehata H, et al. JAK1 rs310241 and JAK3 rs3008 genotypes may increase susceptibility to psoriasis: a case control study. Skin Pharmacol Physiol 2020;33(04): 207-212

105 Zhou J, Li Y, Sun D. Associations between STAT gene polymorphisms and psoriasis in Northeastern China. Dermatology 2017; 233(01):30-36

106 Wang W, Zhu Z, Zhu C, et al. A genetic variant rs1020760at NFKB1 is associated with clinical features of psoriasis vulgaris in a Han Chinese population. Ann Hum Genet 2016;80(04): 197-202

107 Mei Q Liu C, Zhang X, et al. Associations between PTPN2 gene polymorphisms and psoriasis in Northeastern China. Gene 2019; 681:73-79

108 Bin Huraib G, Al Harthi F, Arfin M, Rizvi S, Al-Asmari A. The protein tyrosine phosphatase nonreceptor 22 (PTPN22) R620W functional polymorphism in psoriasis. Clin Med Insights Arthritis Musculoskelet Disord 2018;11:1179544117751434 
109 Dizen-Namdar N, Akcilar R, Bayat Z. Association between Vaspin rs2236242 gene polymorphism and psoriasis vulgaris. Skin Pharmacol Physiol 2020;33(06):317-322

110 Xia T, Diao J, Huang $\mathrm{H}$, et al. Evaluation of the association between CD143 gene polymorphism and psoriasis. Cell Biochem Biophys 2014;70(03):1617-1623

111 Hua S, Fan B, Mao W, et al. Association between PDCD1 gene polymorphisms and psoriasis susceptibility in the Chinese population. Int J Dermatol 2021;60(11):1411-1417
112 Han J, Xiao J, Wu Q, Hao L. Association of ADAM33 gene polymorphisms with psoriasis in a north eastern Chinese population. Mol Biol Rep 2014;41(06): 4001-4005

113 Rajesh D, Nagraj S, Kumar KSP, Kutty AVM, Balakrishna S. Evaluation of HCP5 and Chemokine C Receptor type 5 Gene Polymorphisms in Indian psoriatic patients. Indian J Dermatol 2019;64(03):182-186 